\title{
State of Charge and Lithium Manganate Batteries Internal Resistance Estimation at Low Charge/discharge rates
}

\author{
Xiongping Lin ${ }^{1,2}$, Jieqing Zheng ${ }^{1, *}$, Zheng Zou ${ }^{1, *}$, Feng Lin $^{1}$, Dingrong Deng ${ }^{1}$, Chunyan Cao ${ }^{1}$, \\ Xin Wen ${ }^{l}$, Linhua Que ${ }^{1}$ and Juqiong Yang ${ }^{1}$ \\ ${ }^{1}$ Cleaning Combustion and Energy Utilization Research Center of Fujian Province (Jimei University), \\ Xiamen 361021, PR China \\ ${ }^{2}$ Chengyi College, Jimei University, Xiamen 361021, PR China \\ *E-mail: zhjieqing@126.com, xxzz6670@jmu.edu.cn
}

doi: $10.20964 / 2021.01 .48$

Received: 10 September 2020 / Accepted: 7 November 2020 / Published: 30 November 2020

\begin{abstract}
Several parameters relating to electric vehicles vary with the state of charge (SOC). In currently commonly used equivalent circuit models, changes of the Ohmic resistance $\left(R_{0}\right)$ and polarization resistance $\left(R_{\mathrm{p}}\right)$ during charge and discharge are ignored. Therefore, the models only present high accuracy on specific conditions, which cannot replicate the dynamic characteristics of lithium ion batteries. Parameter identification was performed on open circuit voltage (OCV) and direct-current internal resistance by employing the hybrid pulse power characterization (HPPC) method to improve calculation accuracy. The test result shows that the Ohmic resistance and the total internal resistance are influenced by the rate and the OCV and polarization resistance are significantly affected by the SOC; at different SOCs, the larger the charge and discharge rates are, the larger the polarization resistance of a battery (correspondingly, the greater the change to the curve) and the lower the Ohmic resistance and the total internal resistance of the battery (the less significant the change to their curves).
\end{abstract}

Keywords: Ohmic resistance, polarization resistance, hybrid pulse power characteristics.

\section{$\underline{\text { FULL TEXT }}$}

(C) 2021 The Authors. Published by ESG (www.electrochemsci.org). This article is an open access article distributed under the terms and conditions of the Creative Commons Attribution license (http://creativecommons.org/licenses/by/4.0/). 